\title{
SOCIALISING POSTGRADUATE STUDENTS TO SUCCESS IN AN OPEN AND DISTANCE LEARNING ENVIRONMENT
}

\author{
S. Schulze \\ Department of Psychology of Education \\ University of South Africa \\ Pretoria, South Africa \\ e-mail: schuls@unisa.ac.za
}

\section{ABSTRACT}

The aim of this study was to understand the socialisation of master's and doctoral students towards success in an open and distance learning (ODL) environment. The investigation focused on identifying the people, processes and artefacts that the students believed most contributed to their success. Six doctoral students who had completed their research within three years and five master's degree students who had obtained their degrees with distinction participated in the research. The data were collected by means of graphic elicitation interviews following on the completion of a relational map to give an indication of the strength of the influence. The sociocultural and the social capital theories were used as a lens to interpret the data. The findings indicated what the participants believed mediated their learning and development, increased their zone of proximal development (ZPD) and enabled them to be successful. The study contributes to the debate on the socialisation of postgraduate students towards success without compromising their autonomy.

Keywords: throughput rate of postgraduate students, open and distance learning, the sociocultural theory, social capital, student autonomy, the University of South Africa.

\section{INTRODUCTION}

Universities take the throughput rates of masters and doctoral students seriously and there is much debate about the topic globally and locally (De Beer and Mason 2009; Manathunga 2005; Wisker, Robinson and Shacham 2007). The University of South Africa (Unisa) is no exception, and several publications over the years have pointed out the poor throughput rate of master's and doctoral students at the institution (Brynard 2005; Kritzinger and Loock 2012; Lessing and Schulze 2002; Van der Westhuizen 2013). As academics are urged to increase their throughput rates to enhance the prestige of the institution and to maximise state subsidy, there seems to be different views on the timeliness of the completion of the studies. Some researchers (e.g., Wingfield 2011) have indicated that one model cannot be applied to all students since some of them study full time while others are enrolled on a part-time basis. Significant events also occur in the lives of the students that impact on their studies, such as the birth of a baby or acquiring 
new employment, which need to be considered when using throughput as a barometer of student success. It therefore seems important to investigate effective postgraduate study in consideration of both the throughput rate and the quality of the outcome to enhance an understanding of the factors that enable student success. Additionally, tension seems to exist between the support students need in comparison to the fact that they ought to be able to work independently (Drennan and Clarke 2009; Johnson, Lee and Green 2000; Wisker et al. 2007).

Against the above background, this research is concerned with how students are currently socialised to success. In the research the focus is on supervision in an Open and Distance Learning (ODL) context. In ODL environments, student support is sometimes defined in nonhuman terms, for example, how best to connect the students to functions, systems and various technologies within a virtual environment (McCracken 2008-2009). However, some researchers (e.g., Hopwood 2010) have pointed out that doctoral learning is a social process that involves personal and social learning. Therefore, drawing on the literature on the sociocultural theory, this article explores the nature and role of students' socialisation within the academic community to enable them to complete their studies successfully. Although much of the literature in international publications focuses on the socialisation of students and the roles that relationships play during doctoral research (Boud and Lee 2005; Golde 2000; Paglis, Green and Bauer 2006), there is a paucity of such data in the South African context, particularly in ODL environments and from a sociocultural perspective.

According to the sociocultural theory, pedagogy in a relational sense refers to the initiation of relationships and actions across multiple spaces (places) which provide the potential to learn (Pratt, Tedder, Boyask and Kelly 2013, 46). These spaces include the master's and doctoral students' lives as university students, their personal or private spaces, and their professional or working spaces (e.g., as teachers), and involve the students' physical places as well as their relational spaces of interaction with people and with cultural artefacts. Critical inquiry through the lens of the sociocultural theory could shed light on the kinds of pedagogical activities that the students are involved in and how they learn from these interactions. This could enhance the understanding of the nature of the positive interventions that are required for the successful completion of research projects and dissertations without compromising student autonomy.

Sociocultural theorists argue that student learning and development occur by means of social experiences, when the students interact with people, artefacts (such as books and journals), situations, work contexts or academic institutions and practices (Billet 2006; Lantolf and Thorne 2000). Thus, learning is shaped by the social and cultural contexts of the learning environment and the multifaceted human activity structures within them at any given time. The primary constructs of the sociocultural theory are mediation, internalisation and the Zone of 
Proximal Development (ZPD). Mediation implies that the students' cognitive activities are mediated by symbolic artefacts such as language (the most powerful cultural artefact to mediate connections to others and to the self), concepts and logical argumentation, as well as material artefacts and technologies. Higher-order mental functions such as logical thought and attention are organised by means of the participation in activities such as conferences, workshops and discussions within the academic community. In their taking notes at workshops and conferences, the students create their own artefacts during the social interaction (Hopwood 2010). One form of mediation is regulation. Regulation by means of supervision should culminate in self-regulation (autonomy), which is characterised by the fact that the students are able to accomplish research-related activities with little or no support. Self-regulation is made possible by internalisation. Internalisation refers to the forming and transforming of the students' mental functions by means of interpersonal and person-environment interaction. The key to internalisation resides with the students' capacity to imitate the intentional activities of others, for example, of other researchers. Imitation thus involves goal-directed cognitive activity. The ZPD refers to the difference between the level of development that the student has already reached, and the level that may be reached with assistance. Vygotski (in Lantolf and Thorne 2000, 207) ascertained that 'learning collaboratively with others, particularly in instructional settings, precedes and shapes development'.

Regarding collaborative learning, the social capital theories complement the sociocultural theory by explaining how social networks provide social capital, referred to as 'the intangible resources embedded within interpersonal relationships or social institutions' (Social Capital and Education u.d., 1). Social capital can be provided as social norms such as academic norms that stipulate the criteria for rewarding or sanctioning students' learning outcomes. It is made available as obligations or expectations, and as sources of information. One's peers are also a valuable resource that provides social capital (Trees 2013). A number of researchers (Klenowski, Ehrich, Kapitzke and Trigger 2011; Leshem 2007) have explained the role of cohort groups that function in communities of practice (Wenger 1998) to develop the abilities of postgraduate students. Liaising with fellow students provides informal learning opportunities that enable the students to develop the expertise to complete their degrees successfully. Student networks, particularly face-to-face interactions, provide opportunities for discussions, for benchmarking progress, and for personal support (Baker and Lattuca 2010; Pilbeam, LloydJones and Denyer 2013). The support that the network provides is both of an emotional and an academic nature (Pilbeam et al. 2013). During discussions at an appropriate level, students exchange and develop ideas, as well as find solutions to problems. For example, Leshem (2007) explained in her study how the students developed their understanding of the role of conceptual 
frameworks in doctoral research through various focussed conversations.

In the light of the above exposition, this study sought to investigate the socialisation of postgraduate students who have successfully completed their master's or doctoral studies.

The methodology that was used is explained next.

\section{METHODOLOGY}

The participants were selected a priori from a subset of the master's and doctoral student population. Using purposeful sampling, 11 participants were chosen from a computer-generated list provided by the University and from personal referrals by colleagues. Nine participants were female and two were male. They included a variety of races and cultures (black, white, brown, and Indian participants, and one Chinese). All of them were from the social sciences, and had completed their studies during the previous two years. The criteria for the selection stipulated that the doctoral students (six) had completed their research within a period of three years, and that the master's students (five) had obtained their degrees with distinction. In two instances the students were supervised by both a supervisor and a co-supervisor, and in five instances supervision crossed cultural boundaries. With one exception, the supervisors were all female, while two co-supervisors were male.

The data were collected by means of graphic elicitation interviews, using relational maps (Bagnoli 2009; Crilly, Blackwell and Clarkson 2006). This method allows for the inputs of the interviewees that are difficult to attain in semi-structured interviews. The participants were first provided with a table with three columns. In the first column they had to list the people, artefacts or events within or outside the scholarly community that they believed contributed most towards their success. They had to indicate their relationship with these significant others in the second column (e.g., colleague or supervisor), and in the last column they had to provide key words indicating the meaning of the relationship (e.g., statistical support). During the second phase the participants had to use the information in the table to complete a relational map (Rose 2012) that contained five concentric circles with themselves in the middle. They had to put the most important person/artefact/practice closest to themselves and the inverse for the least important. In the third phase, the interviewees had to explain the relational map to the interviewer. They were then probed for more detail.

In designing and refining the method, two experienced postgraduate supervisors evaluated the table and the relational map, and after some adjustments the method was pilot-tested with one female academic who had just completed her doctorate but who did not form part of the study. The level of reflection and abstract thinking that the method facilitated was encouraging and pointed to a valuable approach. It took the participants about 15 minutes to complete the 
table and the map while the interviews lasted about an hour. The researcher made use of several follow-up e-mail conversations to obtain additional information as needed. For example, a participant may have omitted somebody on the map but referred to that person in the interview, e.g., a psychologist or language editor. In such an instance the participant would then be asked to indicate in which circle he or she would place this person.

Ethical clearance for the study was obtained, as well as the informed assent from all the relevant parties. Tape-recording the interviews and transcribing them verbatim enhanced the trustworthiness of the data, as did the fact that the interviews continued up to the point that data saturation was reached.

Using the theoretical framework as lens to analyse the data, the findings are presented and discussed in terms of mediation, internalisation and the ZPD.

\section{FINDINGS AND DISCUSSION}

\section{Mediation}

The interview data indicated that the supervisors and the support staff, the sources of academic literature, workshops/conferences, language ability, and financial support mediated the students' learning and development. The next sections will clarify these aspects.

\section{Supervisors and support staff}

Even though the aim is the autonomy of the student, research done globally and locally has identified supervisors as the key role-players in students’ success (Buttery and Richter 2005; Ismail, Abiddin, Hassan and Ro’is 2014; Lessing and Schulze 2002; Nulty, Kiley and Meyers 2009). This observation was confirmed in this study. Six of the interviewees positioned their supervisors in the two circles closest to them. The participants explained the significant mediating role of their supervisors by indicating that they set high academic standards; helped to map the research journey in time-frames; were available and approachable when needed; were quick and clear with feedback that included useful examples; were knowledgeable, e.g., with regard to research methods; facilitated the students' critical thinking; provided pastoral care, affirmation and motivation; and offered constructive criticism in addition to technical guidance.

For example, two participants mentioned,

She [the supervisor] sent us [the postgraduate students] a starter pack, which was wonderful. It told us everything ... what font, what referencing techniques, everything. So, that was like my 
Bible next to me. It helped me throughout my studies. And also when I thought: 'Oh my God, I can't do this. I think I am just going to give it up' ... I would put little comments in there, like: 'Prof, do you think this is okay?' And she was so supportive ... she would immediately respond. So I think she was just excellent. (Female, M.Ed. student)

From the outset, she [the supervisor] said to me: 'These are the things that are going to be important'. So the kind of person that I am, I need to see the whole picture first and then work through the detail ... so that really benefited me. I could see these are the chapters, and these chapters are going to impact on those chapters. She gave me a copy of an outline of chapter one which I followed. ... And her responses to me were quite fast and very good. She was not afraid to be critical and she was not afraid to give emotional support. She understood that I have three children and that my daughter was writing matric ... and she was very supportive of that. If she had said to me: 'I need your chapter three in maybe a month's time', and the month came and I had not given her chapter three, she was never mean or nasty. She would send an e-mail to ask: 'Are you alright'? (Female, M.Ed. student).

The above two quotes indicate the importance of initial regulation played by supervisors in order to lead the students to self-regulation. In this regard, support staff members, such as librarians and language editors were also identified by some participants as contributors to their success, although they were always placed on the outer circles. In addition, the one participant who embarked on a quantitative research project placed the statistician that assisted her (the only full time statistician at the institution), on the third closest circle.

She recalled,

I had never done quantitative research before, so it was not my strong point, so I then went to Susan who did a fabulous analysis. She linked the data to my studies. I quite frankly don't know how she managed to do it because the woman was overwhelmed with work. She had a board up there ... and I looked at all of these people she was trying to help. And every time I went there the phone was ringing ... she had papers all over her desk and I could see it was other students' data and she looked absolutely exhausted. (Female, D.Ed. student).

\section{Artefacts: Books and journals}

It is imperative that students enjoy easy access to books and journals in libraries and on the internet for them to be able to work independently (Buttery and Richter 2005). Three of the students were, however, not aware of training in the use of a library and did not understand how to access electronic sources. Eight of the participants who were skilled in doing library searches, placed the library and access to the internet for academic sources within the third circle of their relational maps. They explained the mediating role of books and journal articles to stimulate their thinking and to provide them with information on specific theories, as well as the outcomes of other research. The vast amount of information that was available enabled the participants to identify current trends in their fields, and the important role-players globally and in South 
Africa. Another benefit was that other students' dissertations could serve as examples and benchmarks of what was required and how the research was to be executed.

For example, one participant remarked,

I could look at the structure of other peoples' dissertations, what kind of language they are using ... academic writing is different to ordinary writing. I also looked at people's research and I could see how I could link it to my own work. It makes it so much easier. (Female, M.Ed. student).

I used a lot of library books ... I knew the importance of having up to date research. I also knew that I needed to get to the core. It is like in Law ... you have a pivotal case study. So I knew to look there. But I also made a lot of use of articles that come out every day ... and the key journals ... but also what people are writing about on the net ... that is important for trending. (Female, D.Ed. student).

\section{Conferences and workshops}

Several researchers mentioned that conferences and workshop were valuable for postgraduate students (Buttery and Richter 2005; Wisker et al. 2007). One participant who was not able to make use of his supervisor's attention due to illness, mentioned that he independently gained knowledge and insight through the different conferences and workshops that he attended. Five other participants placed conferences/workshops in the third or fourth spheres. With reference to the workshop on research methods that the institution organised, the participants pointed to the value of these workshops in respect of the supportive friendships that were formed between the students. Hereby their autonomy from the assistance of their supervisors was increased. At the workshops the presenters gave examples from the wealth of their own experiences. Their enthusiasm contributed to the interest of the students attending, and that could be motivational for students’ self-regulation.

For example, one student mentioned,

The presenter was so passionate and so excited about the methods. It really excited me. I had decided to do individual interviews and focus groups, but I ended up with a narrative approach and that was great as I gained so much information! But if I had not thought about what he said ... how you are the creator of your research and you must do it in the way that is going to work for you, but is still valid and reliable. And that stuck with me. So, I think it should be a compulsory workshop. (Female, M.Ed. student).

Other participants attended workshops or conferences on their various research topics, and attested to the value thereof for generating social capital that could be considered as a motivation for self-regulation. 
One example is,

I attended a child trauma conference, and the two women that presented it were very dynamic and inspiring. So, I try to attend their course annually because when I leave I always feel as if I can focus better and can remember why I do what I do. Because I think one can get caught up in little things and become tired and burnt out ... and then their workshops always revive me. (Female, M.Ed. student).

\section{Language}

Since 'all research is a dialogue with other experts' (Wisker et al. 2007, 303), language is an important cultural artefact of academic study (Lowinger, He, Lin and Chang 2014; Son and Park 2014). It provides the conceptual tools to mediate a connection between the students' and others' cognitive activity when engaging with published work, when debating on issues with academics or peers, or through the writing of a research report. Two of the students whose first language was English both attested to the fact that their mastery of English as the academic lingua franca contributed to their success.

One of them noted,

Having the personal skill to write English I think is one of my blessings. Some people don't have that ... they would need support. Some Afrikaans students would need to ensure that they ask, double check, have peer readers or proof readers and exposure to academic writing. (Female, M.Ed. student).

The impact of lacking this proficiency was illustrated by the challenges that the Chinesespeaking student faced. Before enrolling for her studies, she had to study English on a full time basis for 10 months in order to improve her competence in English. However, she still experienced difficulties in the writing of her dissertation. She placed language as artefact in the circle closest to her, illustrating its importance, also with reference to the experiences of other Chinese students studying at Western universities (Lowinger et al. 2014; Son and Park 2014).

She commented,

In the beginning I was struggling but because I had a research background I knew how to write, but changed it to English. So, in the beginning I actually did a lot of translation because my thinking was Chinese. I got my husband to read to see if what I wrote was correct or not ... and he corrected me. And Prof X [the supervisor] also helped me. (Female, D.Ed. student).

\section{Financial support}

Financial support indirectly influences the success of postgraduate study (Buttery and Richter 
2005). In this research, three participants who lacked the financial resources that postgraduate study requires placed the financial support they received on the third or fourth rings of their relational maps. The availability of bursaries is the key that opens doors to computer equipment and internet connectivity, as well as for the opportunity to attend conferences and workshops, which may contribute towards the students’ autonomy and their resultant success.

One participant stated,

I had to take a loan ... I had to go to ask the bank how much they could give me ... because during the first year there were challenges related to registration and buying a laptop, getting a connection, travelling ... The loan was a relief. Without it I would not have had the requisite things in place to start. (Male, D.Ed. student).

\section{Internalisation}

Goal-directed activities and self-regulation are crucial to complete degrees successfully, in particular doctoral degrees. These factors are explained in the next section.

\section{Goal-directed activity}

Researchers (e.g., Ismail et al. 2014) have previously alluded to the importance of mutual agreement on the goals of supervision and the identification of tasks in order to reach the targets that were set. Supervisors also need to model goal-directed activities. Although only three of the participants identified goal-directed activities as key factors that contributed to their success, all three placed them in the first circle of their relational maps, thus highlighting its personal importance. The clear goals that they had set for themselves (e.g., to qualify as educational psychologists), motivated them towards the completion of their studies, enabled autonomous work since it stimulated reflection on what they needed to do to reach their goals.

\section{Self-regulation}

Supervisors wish their students, in particular doctoral students, to become independent and to indicate initiative (Brew and Peseta 2004; Brill, Balcanoff, Land, Gogarty and Turner 2014). However, the expectations between the supervisor and the student may not be the same, leading to tension between guidance and autonomy (Johnson, Lee and Green 2000; Wisker et al. 2007). This tension was alluded to in two instances in this study, namely with regard to the initiation of contact and supervisor feedback. Written feedback of a high quality is an important tool to support the students' ability to develop confidence and autonomy, particularly in an ODL environment (Augustsson and Jaldemark 2014). Feedback includes comments, points of view, 
and instructions and questions. In this study two instances of supervisor neglect was indicated, namely slow feedback (of two months and more), and/or trivial comments. This kind of negligence forced the participants to take control of their studies and to continue independently. In this respect one participant identified and consulted international experts in his field after a communication breakdown between him and his supervisor due to his supervisor's prolonged illness. With the support of a psychologist and a friend (an academic), another participant enforced her supervisor's response, several months after she had submitted work for review, as follows,

I started doing the following: I would send them [supervisor and co-supervisor] an e-mail indicating that I needed to continue, and could we meet the following week on Thursday at ten. And then I would expect them to give me feedback. (Female, D.Ed. student).

The abovementioned example illustrates the social capital value of supportive peers. It also illustrates how students with a robust academic self-efficacy, which refers to their confidence in their own abilities to execute research tasks to achieve academic goals, as well as an intrinsic locus of control, regulate their own learning in the absence of efficient supervision. Researchers have already previously indicated that academic self-efficacy and locus of control predicted academic success (Lowinger et al. 2014; Van der Westhuizen 2013).

\section{Zone of proximal development}

Interaction with others may support students to perform academic work that they are not able to do independently, according to Vygotski (1978). Dissertations need to show evidence of superior intellectual engagement and rationality, while doctoral studies have to be original, and make a significant contribution to new knowledge. Students are not always able to deliver such conceptually complex research outputs on their own. It can, however, be cultivated through learning conversations with supervisors, experts in the academic community, and peers as mentors.

\section{Mentoring}

In addition to coaching students in respect of the task that needs to be completed, supervisors act as mentors who can facilitate students' personal learning (Brill et al. 2014). As mentors, supervisors model appropriate disciplinary-based research behaviour so that students can internalise the behaviour (Manathunga 2007) to become autonomous. This includes the adoption of critical attitudes and the ability to argue their own views, even if these differ from 
those of the mentors/supervisors. Unfortunately, students from some cultures, for example the Chinese culture, are likely to adopt approaches that involve deference to authorities and an uncritical approach (Wisker et al. 2007). With a view to addressing unscholarly work, the participants indicated that their supervisors refused to accept sub-standard work. They facilitated complex conceptualisation and problem-solving through written comments or personal discussion; expected additional reading from the students by referring them to relevant literature that may stimulate greater insight; and asked questions that forced the students to reflect at a deeper level and thus increased their ZPD. In one instance, stimulating proximal interaction was facilitated by communication every second week via electronic media (skype).

The student stated,

I think one is better able to understand face-to-face interaction than with an e-mail. I found that I could better express myself. Skype helped me to discuss issues with my supervisor when I was struggling and needed guidance. In an open and distance learning environment I think it is compulsory. How convenient to sit far away but be able to converse with your mentor ... adding a face and a voice to an e-mail message. (Female, D.Ed. student).

Opportunities to interact with other experts in the scholarly community of practice (Wenger 1998) may also increase the ZPD. A male participant was accordingly able to develop a formula for the assessment of mathematical work at mathematics conferences and workshops. A master's student who contracted the services of an editor explained how he pointed out where her arguments were illogical, where she was long winded or 'waffling'.

\section{Collaboration with peers}

Peers are a valuable source of social capital since peer mentoring can enhance scholarship, and afford an environment favourable for learning both of which are crucial in the student's quest for autonomy and for his/her success (Brill et al. 2014; Pilbeam et al. 2013). Seven of the participants attested to the fact that interaction with other students was invaluable. They placed them in the second to fourth concentric circles of importance. The peers enabled academic discourse that required of them to articulate and discuss their work. Added to this was the motivational value of comparing progress, 'We pushed one another', a participant commented, and added,

We would phone each other and she would complain to me, or I would send her one of my chapters and say: 'Okay, this is what I did ... look at mine', or she would send me hers and say: 'Okay, this is my final chapter ... so look at mine and see if it helps you with your study'. So that is how we helped each other. (Female, M.Ed. student). 
In addition to stimulating critical thinking, peers provide moral support and practical advice on how to address hitches related to research, language difficulties or computer technology, as was found by research by Brill et al. (2014) and Wisker et al. (2007).

\section{CONCLUSION}

This investigation focused on the socialisation of students who had achieved their master's and doctoral degrees with great success, as was indicated by the timely completion or a high quality outcome. The aim with this study was to identify the key role-players, processes and artefacts at the micro level that the students believed contributed most to their success. The innovative use of graphic elicitation interviews which were conducted with eleven successful master's and doctoral students stimulated reflection and generated rich data which enabled the strengths of the influences to be determined.

At the commencement of their studies, specifically, the students were socialised to success by means of efficient and dedicated supervision. This was particularly important for the master's students, but often also for the doctoral students. It is evident that the supervisors were key role-players in the effort to facilitate the success of the students in an ODL environment. The use of social media such as Skype enhanced the interaction between the supervisors and the students. This medium, however, was not used much, and its importance should be further investigated. In this study it was found that those students who did not enjoy efficient supervision and role-modelling but who were nevertheless successful could lay claim to robust academic self-efficacy and strong intrinsic locus of control.

It is crucial that the regulation by a supervisor needs to be transformed into self-regulation. In order for this transformation to be successful the students need to own specific skills, including knowledge of the library and the internet. They also need to be conversant in English to be able to write academic reports in the language. They require exposure to experts at conferences and workshops with on-going peer interaction in an academic context to increase their ZPD and to provide them with social capital. In addition, the social media, such as web pages where the students can interact with one another, could assist in the formation and transformation of the students' mental functions, and thus in their self-regulation. Likewise, the statistical support of students could also play a role, although it was found that more support was needed in this regard.

It is hoped that this study would contribute insight into the way that master's and doctoral students within an ODL environment are socialised towards success. The conclusions could be useful in the debate on the support given to students versus their independence, and they could 
be considered in postgraduate supervision in the future.

\section{REFERENCES}

Augustsson, G. and J. Jaldemark. 2014. Online supervision: A theory of supervisors' strategic communicative influence on student dissertations. Higher Education 67: 19-33.

Bagnoli, A. 2009. Beyond the standard interview: The use of graphic elicitation and arts-based methods. Qualitative Research 9(5): 547-570.

Baker, V. L. and L. R. Lattuca. 2010. Developmental networks and learning: Toward an interdisciplinary perspective on identity development during doctoral study. Studies in Higher Education 35(7): 807-827.

Billet, S. 2006. Relational interdependence between social and individual agency in work and working life. Mind, Culture and Activity 136(1): 53-69.

Boud, D. and A. Lee. 2005. Peer learning as pedagogic discourse for research education. Studies in Higher Education 30(5): 501-516.

Brew, A. and T. Peseta. 2004. Changing postgraduate supervision practice: A programme to encourage learning through reflection and feedback. Innovations in Education and Teaching International 41(1): 5-23.

Brill, J. L., K. K. Balcanoff, D. Land, M. M. Gogarty and F. Turner. 2014. Best practices in doctoral retention: Mentoring. Higher Learning Research Communication 4(2): 26-37.

Brynard, D. J. 2005. The management of the selection and supervision of postgraduate research students in public administration: Facing difficult challenges. Journal of Public Administration 40(3.2): 364-376.

Buttery, E. A. and E. M. Richter. 2005. An overview of the elements that influence efficiency in postgraduate supervisory practice arrangements. The International Journal of Educational Management 19(1): 7-26.

Crilly, N., A. F. Blackwell and P. J. Clarkson. 2006. Graphic elicitation: Using diagrams as interview stimuli. Qualitative Research 6(3): 341-366.

De Beer, M. and R. B. Mason. 2009. Using a blended approach to facilitate postgraduate supervision. Innovations in Education and Teaching International 46(2): 213-227.

Drennan, J. and M. Clarke. 2009. Coursework master's programme: The student's experience of research and research supervision. Studies in Higher Education 34(5): 483-500.

Golde, C. M. 2000. Should I stay or should I go? Student descriptions of the doctoral attrition process. Review of Higher Education 23(2): 199-227.

Hopwood, N. 2010. Doctoral experience and learning from a sociocultural perspective. Studies in Higher Education 35(7): 829-843.

Ismail, A., N. Z. Abiddin, R. Hassan and I. Ro'is. 2014. The profound supervision practice in higher education to enhance student development. Higher Education Studies 4(4): 1-6.

Johnson, L., A. Lee and B. Green. 2000. The Ph.D. and the autonomous self: Gender, rationality and postgraduate pedagogy. Studies in Higher Education 25(2): 135-147.

Klenowski, V., L. Ehrich, C. Kapitzke and K. Trigger. 2011. Building support for learning within a Doctor of Education programme. Teaching in Higher Education 16(6): 681-693.

Kritzinger, E. and M. Loock. 2012. A critical investigation into the current shortage of information technology postgraduates produced by Unisa. http://www.unisa.ac.za/contents/conferences/ odl2012/docs/submissions/ODL-031-2012_Final_KritzingerELoockM.pdf/ (accessed 14 July 2015).

Lantolf, J. P. and S. L. Thorne. 2000. Sociocultural theory and second language learning. In Theories in second language acquisition: An introduction, ed. B. van Patten and J. Williams, 197-221. New 
York: Routledge.

Leshem, S. 2007. Thinking about conceptual frameworks in a research community of practice: A case of a doctoral programme. Innovations in Education and Teaching International 44(3): 287-299.

Lessing A. C. and S. Schulze. 2002. Postgraduate supervision and academic support: Students' perceptions. South African Journal of Higher Education 16(2): 139-149.

Lowinger, R. J., Z. He, M. Lin and M. Chang. 2014. The impact of academic self-efficacy, acculturation difficulties and language abilities on procrastination behavior in Chinese international students. College Student Journal (1): 141-152.

Manathunga, C. 2005. Early warning signs in postgraduate research education: A different approach to timely completions. Teaching in Higher Education 10(2): 219-233.

Manathunga, C. 2007. Supervision as mentoring: The role of power and boundary crossing. Studies in Continuing Education 29(2): 207-221.

McCracken, H. 2008-2009. Best practices in supporting persistence of distance-education students through integrated web-based systems. Journal of College Student Retention: Research, Theory and Practice 10(1): 65-91.

Nulty, D., M. Kiley and N. Meyers. 2009. Promoting and recognising excellence in the supervision of research students: An evidence-based framework. Assessment and Evaluation in Higher Education 34(6): 693-707.

Paglis, L. L., S. G. Green and T. N. Bauer. 2006. Does advisor mentoring add value? A longitudinal study of mentoring and doctoral student outcomes. Research in Higher Education 47(4): 451-476.

Pilbeam, C., G. Lloyd-Jones and D. Denyer. 2013. Leveraging value in doctoral student networks through social capital. Studies in Higher Education 38(10): 1472-1489.

Pratt, N., M. Tedder, R. Boyask and P. Kelly. 2013. Pedagogic relations and professional change: A sociocultural analysis of students' learning in a professional doctorate. Studies in Higher Education 40(1): 43-59.

Rose, G. 2012. Visual methodologies: An introduction to researching with visual materials. $3^{\text {rd }}$ ed. Los Angeles: Sage.

Social Capital and Education. u.d. http://education.stateuniversity.com/pages/2427/Social-CapitalEducation.html/ (accessed 19 February 2015).

Son, J. and S. Park. 2014. Academic experiences of international Ph.D. students in Australian higher education: From an EAP program to a Ph.D. program. International Journal of Pedagogies and Learning 9(1): 26-37.

Trees, K. 2013. Effectively teaching diverse student groups: A reflection on teaching and learning strategies. Australian Journal of Adult Learning 53(2): 234-252.

Van der Westhuizen, S. 2013. Psychological well-being and postgraduate students' academic achievement in research methodology at an ODL institution. South African Journal of Higher Education 27(5): 1324-1342.

Vygotski, L. 1978. Mind in society: The development of higher mental processes. Cambridge, Mass.: Harvard University Press.

Wenger, E. 1998. Communities of practice: Learning, meaning and identity. Cambridge: Cambridge University Press.

Wingfield, B. 2011. Can we improve postgraduate degree throughput rates? South African Journal of Science 107(11/12): 1-2.

Wisker, G., G. Robinson and M. Shacham. 2007. Postgraduate research success: Communities of practice involving cohorts, guardian supervisors and online communities. Innovations in Education and Teaching 44(3): 301-321. 